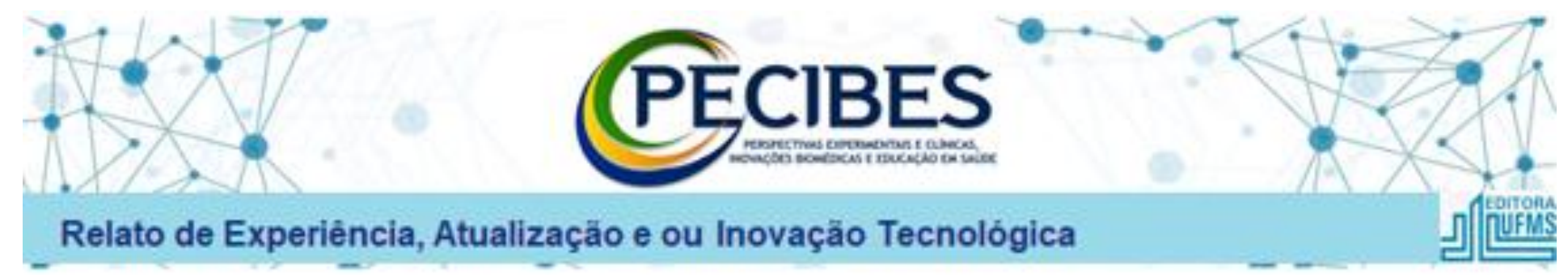

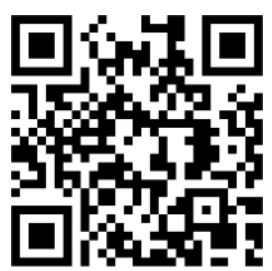

http://www.seer.ufms.br/in dex.php/pecibes/index

\author{
*Autor \\ correspondente: \\ Milena Nunes de \\ Oliveira da Silva, \\ Univerdade Federal de \\ Mato Grosso do Sul. \\ E-mail do autor: \\ milena.nunes@ufms.b
}

$\mathrm{r}$

Palavras-chave:

Estágio. Formação.

Neurofuncional.

Competência.

Habilidade.

Key-words: Internship.

Formation.

Neurofunctional.

Competence. Abiliity.

\section{O protagonismo do estágio na promoção de competências e habilidades na formação do profissional de Fisioterapia: um relato de experiência}

The protagonism of the internship in promoting skills and abilities in the training of the Physiotherapy professional: an experience report

Milena Nunes de Oliveira da Silva ${ }^{1}$, Isabela Corrêa de Paula ${ }^{2}$, Evandro Gonzales Tarnhovi ${ }^{3}$, Juliana Teixeira de Almeida ${ }^{4}$

${ }^{1}$ Universidade Federal de Mato Grosso do Sul, Graduação em Fisioterapia.

${ }^{2}$ Universidade Federal de Mato Grosso do Sul, Graduação em Fisioterapia.

${ }^{3}$ Universidade Federal de Mato Grosso do Sul, Docente do curso de Fisioterapia.

${ }^{4}$ Universidade Federal de Mato Grosso do Sul, Fisioterapeuta.

Resumo

O presente relato de experiência aponta a importância do estágio prático para a promoção de competências e habilidades no futuro profissional de Fisioterapia. É exemplificada a vivência no território II, com ênfase na área neurofuncional, no qual foi possível avaliar, traçar objetivos e condutas, bem como realizar atendimentos de pacientes com alguma disfunção do Sistema Nervoso Central. O estágio foi realizado, sob supervisão direta, na Clínica Escola Integrada da Univerdade Federal de Mato Grosso do Sul, no período compreendido entre agosto e setembro de 2021. Como resultado é possível encontrar a relevância do estágio prático em diversas áreas, como em neurofuncional, para a formação do profissional de fisioterapia, tornando-o mais capacitado para o seu futuro mercado de trabalho.

\section{Abstract}

This experience report points out the importance of the practical internship for the promotion of skills and abilities in the future professional of Physiotherapy. The experience in territory II is exemplified, with an emphasis on the neurofunctional area, in which it was possible to assess, trace objectives and conduct, as well as provide care to patients with some dysfunction of the Central Nervous System. The internship was carried out, under direct supervision, at the Integrated School Clinic of the Federal University of Mato Grosso do Sul, between August and September 2021. As a result, it is possible to find the relevance of the practical internship in several areas, such as neurofunctional, for the training of physiotherapy professionals, making them more qualified for their future job market. 


\section{Introdução}

O Conselho Federal de Fisioterapia e Terapia Ocupacional (COFFITO) define fisioterapia como "uma ciência da saúde que estuda, previne e trata os distúrbios cinéticos funcionais intercorrentes em órgãos e sistemas do corpo humano, gerados por alterações genéticas, por traumas e por doenças adquiridas"(COFFITO). Tendo isso em vista, o fisioterapeuta é um profissional generalista, capaz de atuar em todos os níveis de atenção à saúde e de ter como objeto de estudo o movimento humano, tendo como alvo a promoção, prevenção, tratamento e reabilitação. (Brasil, 2001)

A fisioterapia possui diversas especialidades reconhecidas pelo COFFITO, 15 no total, sendo a Neurofuncional uma delas (COFFITO). Essa especialidade atua na promoção, prevenção e recuperação das funções sensório-motoras (Bertoldi et al., 2011)

Como forma de promover conhecimento e prática aos alunos do curso de Fisioterapia da Univerdade Federal de Mato Grosso do Sul, é ofertado o estágio obrigatório, em nível ambulatorial, onde o foco dos atendimentos são pessoas com disfunções do SNC, tendo como objetivo a reabilitação desses pacientes.

\section{Material e Métodos}

O presente estudo trata-se de um relato de experiencia, do tipo descritivo, realizado por uma estagiária do curso de Fisioterapia, sob a orientação do supervisor no território de estágio. Todos os atendimentos foram realizados na Clínica Escola Integrada (CEI) da UFMS, no período de 03 de agosto à 28 de setembro de 2021, sendo realizados duas vezes por semana, às terças e quintas feiras.

Para se iniciar os atendimentos foi realizada uma avaliação a fím de obter o diagnóstico fisioterapêutico deste paciente e assim ser capaz de traçar os objetivos e condutas para o mesmo.

\subsection{Avaliação}

Para realizar a avaliação é utilizada uma ficha padronizada onde deverá constar: identificação do paciente; seu diagnóstico; determinantes de saúde; queixa principal; história da molestia atual; exames complementares, como raio- $X$, ressonância magnética, entre outros; uso de meio auxiliares de marcha, órteses e/ou próteses; aspectos emocionais, cognição e grau de consciência.

\subsubsection{Exame físico}

O exame físico consistia na avaliação dos dados vitais; da sensibilidade; do sistema motor, analisando a força do paciente, tanto em grupos musculares quanto a dinamometria de pressão manual; da presença de encurtamentos e deformidades; do trofismo e tônus muscular; dos reflexos; da presença de movimentos involuntários; da coordenação motora; do equilíbrio; das aquisições motoras, como o rolar e as mudanças de decúbito; do tipo e fases da marcha; e a capacidade de realização das atividades de vida diária (AVD).

\subsection{Atendimentos}

Para a realização dos atendimentos, existia uma grande variedade de recursos para ser utilizado no ginásio de cinesioterapia. Halteres, caneleiras, thera-band, espaldar, balance pad, discos de equilíbrio, piscina aquecida (hidroterapia) e mesa ortostática são alguns dos recursos disponíveis para os atendimentos.

A disponilibilização desses recursos é de suma importância, uma vez que dá liberdade ao estagiário para a realização de condutas diversificadas e cada vez mais interessante para o paciente. Além disso, fica possível reconhecer qual recurso proporciona mais benefício para o paciente em questão.

\section{Resultados}

Como resultado do processo de avaliação, foi possível identificar as necessidades de cada paciente e tratálas de modo individual e integral, visando sua qualidade de vida.

Quanto ao período do estágio para o aluno, podese observar a importância da prática na área neurofuncional para os alunos que em breve estarão inseridos no mercado de trabalho e irão se deparar com pacientes que possuam alguma disfunção do SNC e assim estarão capacitados para realizar uma boa avaliação, para traçar seus objetivos e condutas, visto que já tiveram um contato prévio.

\section{Discussão}

As Diretrizes Curriculares Nacionais dos Cursos de Fisioterapia (DCN/FISIO) exigem o desenvolvimento do estágio curricular sob a supervisão docente (BRASIL, 2002). As DCN foram criadas para gerar uma perspectiva mais dinâmica na montagem dos currículos das Instituições de Ensino Superior (Moreira et al., 2015; Andrade, 2010).

E objetivo da formação profissional do fisioterapeuta gerar diversas competências e habilidades, dentre elas a atenção à saúde, onde o profissional deverá estar apto a desenvolver a prevenção, promoção, proteção e reabilitação da saúde de seus pacientes. (Brasil, 2001)

Outra competência desenvolvida nesse tipo de formação é a tomada de decisões. Segundo o Ministério da Educação (MEC), os profissionais de saúde devem tomar decisões que visem o uso apropriado da força de trabalho, de equipamentos e procedimentos, pontos que durante a prática do estágio são desenvolvidos. (Brasil, 2001)

Levando isso em consideração, a dinâmica de possuir um território de estágio na qual gere competências no aluno é de suma importância, uma vez que dessa forma o mesmo estará apto para a execução de sua profissão ao egressar da faculdade. Além disso, com a prática o aluno se sentirá mais confiante e seguro ao se deparar com o mercado de trabalho que o espera fora do âmbito educacional.

É possível verificar que durante a prática no estágio as competências e habilidades específicas mais trabalhadas são quanto à manutenção da saúde, bem estar e qualidade de 
vida do paciente, considerando suas circunstâncias éticas, politicas, sociais, economicas, ambientais e biológicas, uma vez que ao estar lidando com um paciente deve-se ter esse olhar biopsicossocial para com ele.

A ficha padronizada, utilizada no território de estágio de neurofuncional, permite ao aluno colocar em prática a competência relacionada à avaliações e reavaliações com coleta de dados, interpretação de exames complementares a fim de se elaborar um diagnóstico fisioterapêutico ao paciente, além de planejar os objetivos e condutas para o mesmo.

Ante o exposto, a experiência vivida pelo aluno durante o estágio se faz necessária para adquirir as competências e habilidades essenciais para se tornar um fisioterapeuta passível de exercício da profissão nas diversas áreas de atuação, tendo como exemplo a área neurofuncional.

\section{Declaração}

O presente relato de experiência não apresenta conflito de interesses e nem patrocínio. O mesmo foi planejado e executado por uma aluna do curso de Fisioterapia sob supervisão direta do professor Evandro Gonzales Tarnhovi, na Clínica Escola Integrada, pertencente à Univerdade Federal de Mato Grosso do Sul.

\section{Referências}

COFFITO . Formação acadêmica e profissional. Disponível em: https://www.coffito.gov.br/nsite/?page_id=2344 acesso em: 30 set 2021 .

Brasil, Ministério Da Educação. Conselho Nacional De Educação. Parecer CNE/CES 1.210/2001. Diário Oficial da União, 10/12/2001, seção 1, p.22. Disponível em: http://portal.mec.gov.br/cne/arquivos/pdf/pces121 0_01.pdf . Acesso em: 30 set 2021.

Bertoldi ALS, Israel VL e Ladewig I. O papel da atenção na fisioterapia neurofuncional. Fisioterapia $e$ Pesquisa, 18 (2) 195-200, 2011. Disponível em: https://www.scielo.br/j/fp/a/Q335FmbqQZTnmq XhfnyfPsP/?lang=pt . Acesso em: 30 set 2021.

Brasil. Conselho Nacional De Educação. Câmara De Educação Superior. Resolução CNS/CES 4, de 19 de Fevereiro de 2002. Institui Diretrizes Curriculares Nacionais do Curso de Graduação em Fisioterapia. Disponível em: http://portal.mec.gov.br/cne/arquivos/pdf/CES042 002.pdf . Acesso em: 30 set 2021.

Moreira COF, Dias MSA. Diretrizes Curriculares na saúde e as mudanças nos modelos de saúde e de educação. Arquivos Brasileiros de Ciencias de
Saúde, 40 (3), 2015. Disponível em: https://www.portalnepas.org.br/abcshs/article/view /811 .Acesso em: 30 set 2021.

Andrade PM de O. Avaliação do estágio da fisioterapia conforme as diretrizes curriculares e a perspectiva biopsicossocial da organização mundial de saúde. Avaliação, Campinas; Sorocaba, 15(2), 2010. Disponível em: http://periodicos.uniso.br/ojs/index.php/avaliacao/a rticle/view/862 . Acesso em: 30 set 2021. 